\title{
Past, present, and future: Critical analysis of use of gastric bands in obese patients
}

This article was published in the following Dove Press journal:

Diabetes, Metabolic Syndrome and Obesity:Targets and Therapy

31 March 2010

Number of times this article has been viewed

\section{Brad Snyder \\ Todd Wilson \\ Sheilendra Mehta \\ Kulvinder Bajwa \\ Emily Robinson \\ Todd Worley \\ Kanayochukwu Aluka \\ Carol Wolin-Riklin \\ Erik Wilson}

Department of Surgery, University of Texas Health Sciences Center at Houston, TX, USA
Correspondence: Brad Snyder

University of Texas, Health Sciences

Center at Houston, TX, USA

Tel + I 7135007250

Fax +I 7135007268

Email brad.snyder@uth.tmc.edu

\begin{abstract}
Adjustable gastric banding (AGB) is quickly becoming the most popular bariatric operation performed in the United States and Canada. Patients are particularly fond of the simplicity of the tool, the relatively low morbidity of the surgery, the quick recovery, and overall results. The gastric band has evolved over its 35-year history into a very successful adjustable tool used to restrict food consumption and limit caloric intake. The percent of excessive weight loss after banding can range from $30 \%-60 \%$ and depends on the time out from surgery. Along with weight loss, there is good resolution of the co-morbid conditions that are associated with excess weight and improvements in quality of life demonstrated after banding. Nutrition and follow up are extremely important after banding to ensure good compliance and adequate weight loss. Failure to follow the postoperative diet, exercise regiment, or mechanical failure of the band can lead to failure to lose adequate weight. While there are particular early and late complications associated with this surgery, the safety profile of the AGB is very appealing when compared to other bariatric operations. As we continue to reduce the morbidity of the procedure, the simple adjustable band concept has a lot of potential to remain a primary technique of maintaining long term weight loss. In conclusion, AGB has and continues to play an important role in the treatment of morbid obesity. It offers reasonably good weight loss results with very little morbidity, and the future of the adjustable band is bright.
\end{abstract}

Keywords: adjustable band, gastric, bariatric, operation, surgery, weight loss, lap-band

\section{Introduction}

While gastric bypass surgery has been at the forefront of weight loss surgery since the 1960 s, adjustable gastric banding (AGB) is quickly becoming the most popular procedure performed in the US and Canada. Of the 220,000 bariatric operations performed in the US and Canada last year, $42.3 \%$ were an AGB operation, which is an increase from the $24.4 \%$ five years ago, while the percentage of gastric bypasses decreased from $65.1 \%$ to $49.0 \%$ over the same time period. ${ }^{1}$ Clearly, there is a substantial US market for AGB, and patients are particularly fond of the simplicity of the tool, the relatively low morbidity of the surgery, the quick recovery, and overall results.

This review is intended to give an unbiased view of the role that gastric banding has played in the treatment of morbid obesity. Therefore, it will address the history of banding and discuss the evolution of this restrictive procedure. Bringing us to modern day banding, we will scrutinize the short-term weight loss result and how weight loss is maintained during the intermediate time period. Long-term weight loss results are examined, and the band's ability to resolve comorbid conditions related to excessive weight and its effects on patient quality of life are discussed. A substantial change in

submit your manuscript | www.dovepress.con 
the patient's behavior with food and a strict diet is a must for good results, and the nutritional considerations after banding are discussed. Complications and failure rates are scrutinized with respect to the low morbidity and mortality of AGB. Finally, results with AGB are compared with other weight loss operations, and we look into the future prospects of AGB.

\section{History and types of gastric banding Origins of the nonadjustable band}

In the summer of 1974, after becoming "disenchanted" with gastric bypass procedures for the treatment of morbid obesity and its complications, a Dr Wilkinson began to experiment with limiting caloric intake and increasing early satiety by decreasing the reservoir capacity of the stomach. However, his goal was to accomplish this while maintaining the normal continuity of the gastrointestinal tract. Dr Wilkinson inverted the lesser curvature into the greater curvature of the stomach and then wrapped the entire stomach with polypropylene mesh. In 1976, he reported combining this procedure with a Nissen fundoplication to prevent reflux and achieving satisfactory weight loss in 99 of 100 patients. $^{2}$

In 1978, Drs Wilkinson and Peloso changed the procedure by placing a $2 \mathrm{~cm}$ polypropylene mesh around the upper part of the stomach. ${ }^{3}$ In the US, Europe, and Australia, surgeons were implanting not only polypropylene mesh bands but also Dacron, silicone-covered, and GORE-TEX ${ }^{\circledR}$ meshes. $^{4-7}$ A special polypropylene clip was also used for restriction. ${ }^{8}$ Difficulty in achieving proper restriction, food intolerance, and emesis because of stenosis of the gastric pouch outlet, band displacement, band erosion, esophagitis, and Barrett's esophagus necessitated reoperation for band correction or removal with conversion to vertical-banded gastroplasty for many of these early procedures. In 1994, despite initially having successful weight loss with nonadjustable mesh band, Naslund et al reviewed their 12-year data which revealed that this procedure was fraught with complications over the time period of the study; specifically, only $31 \%$ of patients had an intact band in their long-term data. ${ }^{9}$

\section{Logical step of adjustability}

Considering the complications of nonadjustable gastric banding, two pioneers began to work on the ingenious concept of adjustability. In the mid-1980s in Innsbruck, Austria, a surgeon named Szinicz and his colleagues began placing silicone gastric bands in animals and called the procedure "reversible gastric banding". He saw the potential in changing the degree of gastric restriction over time. ${ }^{10}$
Likewise, another surgeon named Lubomyr Kuzmak, a Ukrainian immigrant to the US, also recognized the potential of adjustability and the tolerability of silicone. In 1986, he reported on the implantation of adjustable silicone gastric bands in humans, and described better results with adjustable silicone bands compared with the nonadjustable silicone band he had been using since $1983 .{ }^{11}$ His band was less invasive to the stomach, was adjustable, and also reversible. ${ }^{12}$

\section{Laparoscopy}

Surgeons and scientists now had the concept and materials for success. Fortuitous in the late 1980s was the advent of laparoscopy, and it seemed only reasonable to convert this previously open procedure to a laparoscopic procedure to decrease perioperative morbidity and mortality and to increase its attractiveness to patients. Broadbent et al in Australia and Catona et al in Italy reported on the laparoscopic placement of nonadjustable gastric bands in February and May 1993, respectively, and the latter group realized that stenosis of the gastric pouch outlet was a major problem with these bands. ${ }^{13,14} \mathrm{~A}$ few surgeons saw the potential of Kuzmak's adjustable band and in 1993, the first laparoscopic adjustable silicone gastric band was placed in a human by Belachew et al in Huy, Belgium. They had been successfully placing adjustable silicone gastric bands laparoscopically in animals for two years prior and, in 1998, reported the efficacy of adjustable silicone gastric banding compared with vertical-banded gastroplasty. ${ }^{15}$ In the meantime, surgeons began training to place the laparoscopic adjustable silicone gastric band and in July 1994 the LAP-BAND ${ }^{\circledR}$ system (Allergan Inc., Irvine, CA) became available. The Food and Drug Administration (FDA) approved clinical trials in selected centers in the US in 1995. Finally, in 2001, the LAP-BAND obtained FDA approval and has since been become an important surgical treatment for morbid obesity. ${ }^{12}$

\section{Market today}

There have been several modifications to the laparoscopic adjustable silicone gastric band since approval of the LAPBAND system in 2001. Four versions of the adjustable gastric band now exist worldwide.

The two US-approved bands are the LAP-BAND system and the REALIZE ${ }^{\circledR}$ band (Ethicon Endo-Surgery Inc., Johnson and Johnson, New Brunswick, NJ). The LAP-BAND is a low-pressure, silicone band that uses Omniform ${ }^{\circledR}$ technology comprising soft, precurved, and individual sections that create a $360^{\circ}$ inflation area to prevent creases or folds that may lead to band damage. The two types are the AP standard and AP 
large. The REALIZE band AGB-C is the Johnson and Johnson version of the Swedish Band. It is a low-pressure, silicone band made to be one-size-fits-all. The rationale for this band is that a balloon not under high pressure is able to conform to tissue more easily than a band under high pressure.

Two laparoscopic adjustable silicone gastric band companies make bands for use in Europe, ie, MIDBAND ${ }^{\circledR}$ and Helioscopie. The MIDBAND is a low-pressure, silicone band also in use in Latin America as well as in Europe. The French company Helioscopie makes several versions of the HELIOGAST ${ }^{\circledR}$ band in different sizes with three different ports. Several other bands are still in existence and in circulation, and there are some bands made only for limited markets; however, the MIDBAND and the Helioscopie are the major gastric bands produced and marketed in Europe today.

\section{Results of laparoscopic adjustable gastric banding}

\section{Short-term weight loss}

The main reason AGB has gained more market share in the arena of bariatric surgery around the world is the equitable results in weight loss without the morbidity of the laparoscopic roux-en-Y gastric bypass (LRYGB). However, around the world, results are reported in different ways. Most programs report their results as percentage of excess weight lost (\%EWL) although there are other measurements of success, ie, percentage of body mass index (BMI) lost, reduction in BMI, improvement in obesity-related medical illnesses, and improvement in other quality of life (QoL) indicators. What these alternative categories lack is an adequate duration of followup for the results reported. Most of the comparative literature in bariatric surgery is retrospective data over a short time period, usually two to three years. The US literature also lags behind the rest of the world because of the late adoption by the FDA (1992 versus 2001) of the LAP-BAND and now (1994 versus 2007), the REALIZE band. Therefore, longterm data in the US is extrapolated from the placement and followup of these bands in Europe, Asia, and Australia.

Longer followup is possible in places like Europe because of surgical services being provided by a national healthcare service with followup in a nationally enrolled patient program across a smaller geographic area. The short-term post-surgical weight loss time frame is generally regarded as less than three years. Short-term has also been broken down into six months, one year, 18 months, two years, and then three years in various studies. ${ }^{16-20}$ These results set the realistic expectations for patients, but they also can show slow, sustained weight loss with laparoscopic AGB with time, as opposed to quicker weight loss in the first year with the LRYGB.

There are several small and large studies which show a variation on the results above, but these numbers are consistently validated across the world (see Figure 1).

\section{Long-term weight loss}

Longer followup has been reported up to 12 years, ${ }^{16}$ but it is sparse in the US literature. Long-term time frame is measured at more than three years after surgical intervention. Most

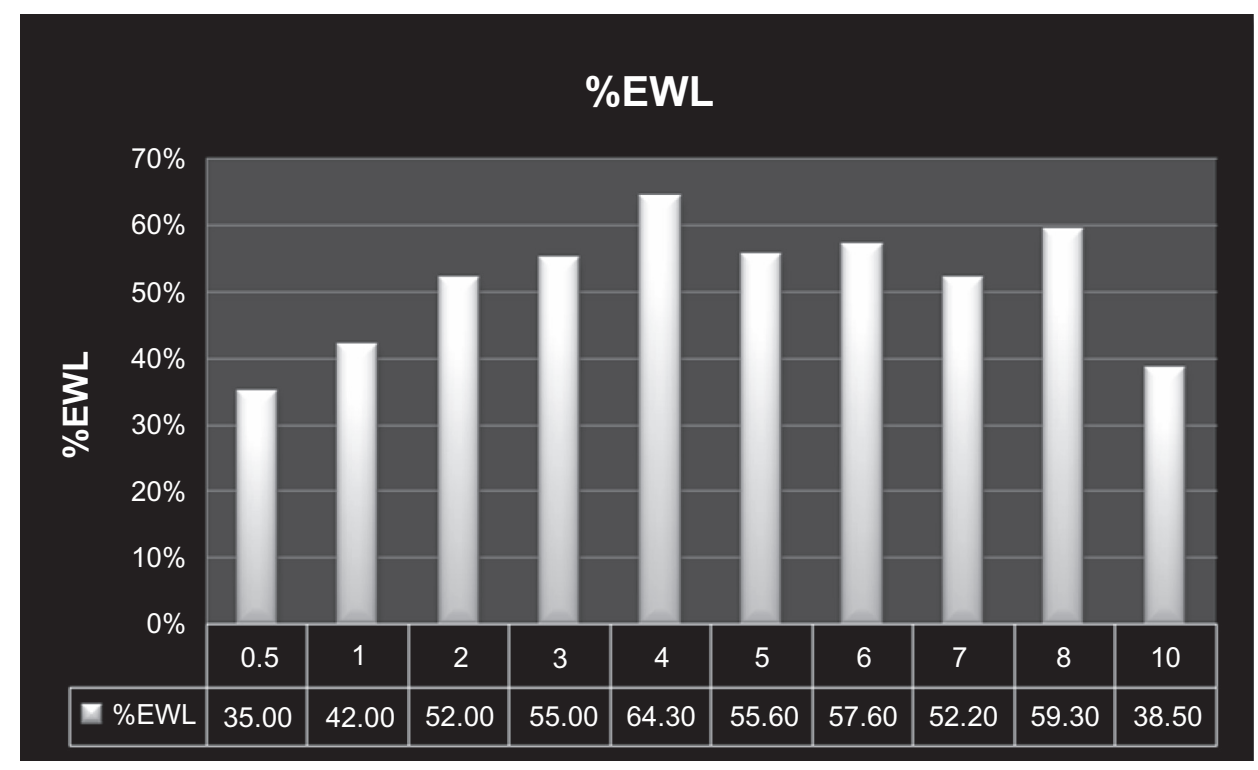

Figure I Percentage excess weight loss results for the adjustable gastric band over years out from surgery. ${ }^{16-2 \mid}$ Abbreviation: \%EWL, percentage estimated weight loss. 
long-term data is from Europe because of the more robust followup in Europe as a result of the National Health Service and its ability to track a less mobile population over a smaller geographic area. American studies have an average followup of about $50 \%$ versus about $90 \%$ in Europe. ${ }^{16,18}$ The long-term weight loss results are shown in Figure 1.

Other factors influence sustained weight loss over the long term. One is the presence of comprehensive weight loss centers versus only surgical followup for adjustments. The other factor is the existence of support groups which are helpful after the initial weight loss has occurred. More parameters are being measured to help understand adherence to lifestyle change through the years. Reaching realistic weight loss expectations, improvement in comorbidities, and cumulative QoL surveys are being collected to show why there is a variance in long-term data from different centers and between areas of the world.

\section{Resolution of comorbid conditions}

Along with weight loss, bariatric surgeons want to measure resolution of comorbid conditions that are associated with excess weight. Most research shows an improvement in Type 2 diabetes $^{22,23}$ (79\%-81\%), metabolic syndrome (78\%) hypertension (67\%), dyslipidemia (66\%), reflux (66\%), asthma $(57 \%)$, arthritis/joint pain (70\%), polycystic ovary syndrome (48\%), and depression (57\%). ${ }^{23-25}$ Unlike the metabolic effects seen with bypass procedures such as gastric bypass and duodenal switch, the remission or improvement in conditions such as
Type 2 diabetes and metabolic syndrome after AGB is believed to be because of the direct effects of weight loss. Therefore, the time required to see improvement in these conditions can vary substantially, and is dependent on the amount of weight loss. In our own cohort of 342 gastric banding patients we found a correlation between weight loss and improvement in comorbid conditions $(\mathrm{r}=0.90)$. This result was anticipated and is logical. If the excess weight causes the conditions, they should resolve with the loss of the excess weight.

\section{Changes in quality of life}

There have also been improvements in QoL demonstrated after banding, using many methods including the Short Form-36 Health Survey (SF-36). ${ }^{23-25}$ Nonetheless, there is no consensus on QoL tools that should be used, nor if the results are lasting. There definitely seems to be a "honeymoon" phase of improvement in QoL for patients, but there seems to be a drift downward in their scores after this. We have demonstrated this using the MooreheadArdelt Quality of Life Questionnaire-II over a three-year period in 342 AGB patients. The significant improvement in QoL lasted for approximately 15 months and then dropped below statistical significance for the rest of the study period (see Figure 2). QoL did not correlate with time since surgery $(r=-0.33)$, nor did any of its components. Furthermore, there was no correlation of QoL with weight loss or resolution of comorbid conditions $(\mathrm{R}=-0.02$ and 0.18 , respectively).

\section{Overall quality of life}

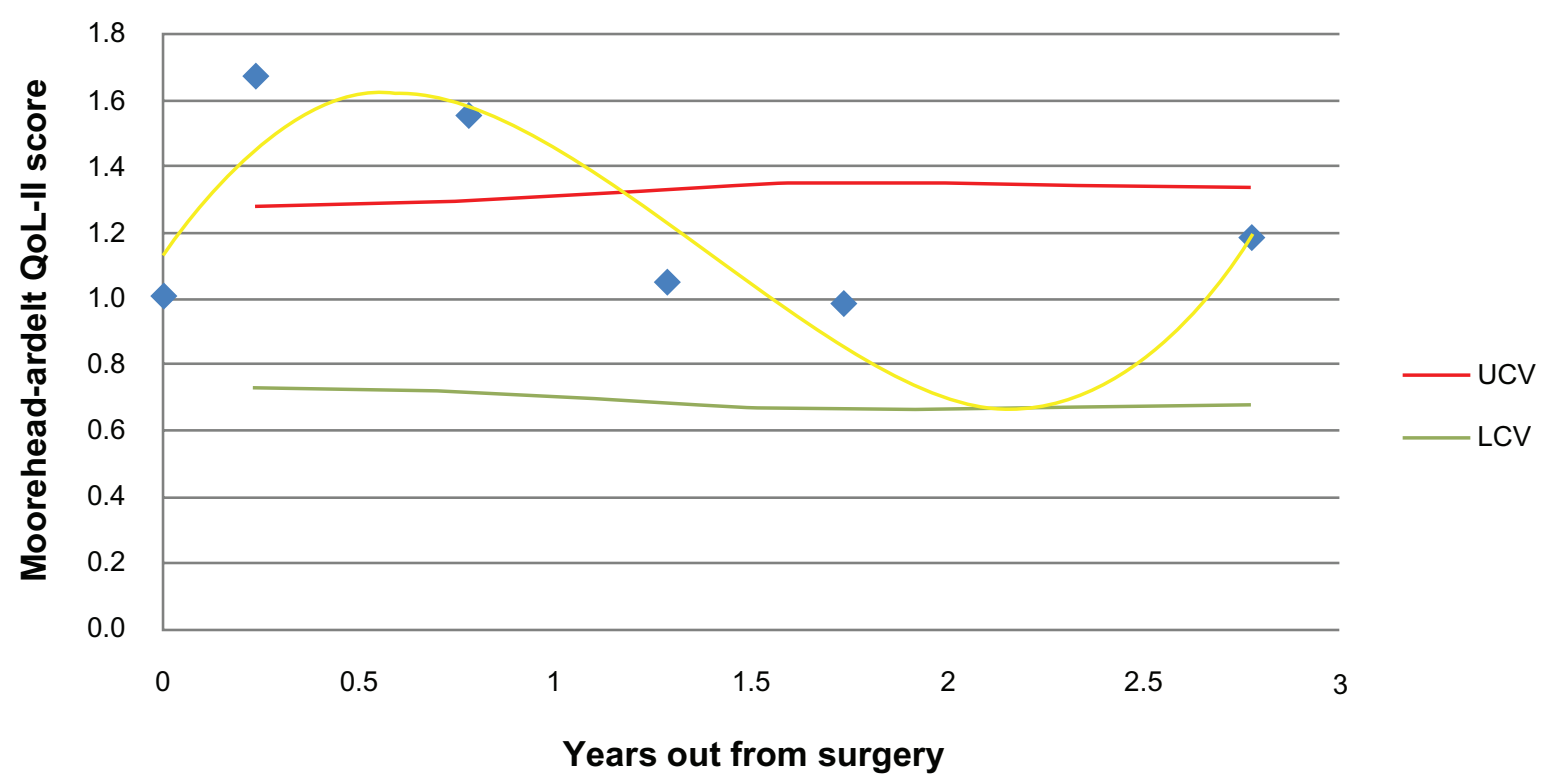

Figure 2 Shows the best fit line for the quality of life score. The upper critical value (UCV) and lower critical value (LCV) are drawn to represent the values of the mean that are significantly different from the preoperative value and have a $P<0.01$. 


\section{Maintenance}

\section{Followup}

Laparoscopic AGB is an effective weight loss procedure, with the majority of patients losing between $44 \%$ and $55 \%$ of their excess body weight. ${ }^{26}$ Typically this technique results in a slower weight loss than LRYGB, with \%EWL stabilizing over a four-year time frame. ${ }^{27}$ However, there are many factors that influence weight loss results seen with banding. Not only is the surgical technique of band placement important, ${ }^{28}$ but also close patient followup with band adjustments is essential in achieving successful weight loss. ${ }^{29,30}$ Band adjustments typically begin one month after surgery, with further monthly adjustments during the first six months, and usually restriction is achieved. Frequent visits are expected, for example every three to six months, to ensure ongoing compliance and weight loss. Thereafter followup should occur as needed based on restriction, weight loss, and potential complications. ${ }^{31}$ Suboptimal followup of the patient may contribute to poor outcomes. Shen et al demonstrated that patients who were seen in clinic six times or more after gastric banding had a significantly greater reduction in \%EWL than patients who returned less frequently. ${ }^{32}$ Patient motivation as well as surgical team support is needed to achieve optimal weight loss after banding. In addition, nutritional education and dietary compliance are likely to be the most important elements for achieving successful weight loss and maintenance.

\section{Nutrition}

The adjustable gastric band is a purely restrictive bariatric procedure. The gastrointestinal tract is not altered and malabsorption of nutrients is not a feature of this procedure. Success of the adjustable gastric band surgery in promoting weight loss is based on the patient consuming a lesser volume of food that will promote a sense of early satiety because of a restricted proximal gastric pouch size.

Banding requires that a patient make dietary and behavioral adjustments to cope with their changed gastric ability. ${ }^{33}$ High-risk eating habits such as grazing, and emotional or mindless eating should be avoided because these behavior traits will hinder weight loss. ${ }^{34}$ The patient must be an active participant in helping to create a proper stoma size by monitoring the volume of food they consume until they feel satiated and there are changes in their weight status. Appropriate band-fill adjustments will facilitate weight loss and preserve esophageal integrity. If a band is filled too tightly, the patient may experience signs of heartburn, regurgitation, and esophageal irritation. ${ }^{35}$
Volume restriction on the amount of food consumed places all gastric banding patients at risk of nutrient compromise ${ }^{36}$ More prevalent nutritional deficiencies following AGB placement include those of iron, folate, thiamine, vitamin $\mathrm{B}_{12}$, and vitamin D. ${ }^{37}$ Supplementation with a multivitamin and mineral compound and assessment of nutritional and metabolic parameters on a regular basis can help to prevent nutritional compromise following ABG placement. ${ }^{38,39}$ Large supplement tablets may not be tolerated because of a restricted gastric stoma size. Adult chewable or liquid multivitamin and mineral preparations will be better tolerated because they can easily pass through a narrow gastric stoma.

An example of the nutritional information given to banded patients would be as follows:

- Liquids should be zero calories and noncarbonated: 48-64 ounces should be consumed daily to maintain adequate hydration status.

- Soft foods that can slip and slide past the AGB will not help signal satiety or control physical hunger, and should be avoided. These foods include cream soups, yogurt, chips, crackers, pretzels, ice cream, shakes, and smoothies.

- Solid foods will help to create a sense of satiety and fullness, eg, chicken, ground beef, fish, seafood, turkey, pork, lean sliced deli meat, and low fat cheese.

- Avoid fatty and greasy foods; instead bake, broil, steam, grill, or roast foods.

- Avoid cream and butter sauces.

- Separate liquids and solids, and drink 30 minutes before or after a meal.

- Consume three meals daily, limiting meal times to 30 minutes. This will help to confer a sense of satiety and avoid the pitfalls of grazing or munching on food in between meals.

- Snack only if hungry, limiting snacks to 150 calories. Do not turn snacks into mini meals.

- Avoid grazing, and mindless or emotional eating. These are high-risk eating habits that can promote weight plateau or weight gain.

Maximizing postoperative weight loss success can be obtained by making long-lasting nutritional lifestyle changes. The dietitian's role in the preoperative and postoperative diet education process and reinforcement of behavioral compliance is crucial to a sustained weight loss and healthy outcome. $^{40}$

Without reasonable expectations, good followup for adjustments, adequate education on life style, and dietary modifications needed for success, then failure to lose ade- 
quate weight after AGB is a real possibility that may lead to high conversion rates to other procedures.

\section{Failure rates}

As a result of the rigorous followup and dietary changes needed, the AGB has the greatest variation in its level of success. Currently, there is no consensus of a formal definition of failure, but most definitions reported focus around a failure to achieve a satisfactory $\% \mathrm{EWL}$ or a certain reduction in BMI.

Failure rates in the first several years after surgery range from $10 \%-20 \%$, with greater failure rates occurring the longer the band is in place. In Finland, where they have a longer experience with the low-pressure systems we use in the US, failure to achieve $25 \% \mathrm{EWL}$ is reported in $15 \%$ of patients during the first one to three years, and with an increase in failure rate of $40 \%$ during the eighth and ninth postoperative years. ${ }^{41}$ In Sweden, where the same banding systems are utilized, a report of 824 patients with an average preoperative BMI of $43 \mathrm{~kg} / \mathrm{m}^{2}$ demonstrated a $5 \%$ reoperation rate secondary to insufficient weight loss. ${ }^{42}$

In the US, similar failure rates are seen. A study from Irvine Medical Center where 250 patients were randomly assigned to gastric bypass versus gastric banding reported that $16.7 \%$ of patients in the gastric banding arm failed to achieve $20 \%$ EWL. ${ }^{20}$ Of 484 patients at the University of Texas Medical School in Houston, $15 \%$ failed to achieve $30 \%$ EWL at one year. ${ }^{43}$ Smaller studies across the US report similar failure rates. ${ }^{44,45}$

It is difficult, if not impossible, to predict which patients will or will not have poor weight loss after an AGB operation. Snyder et al showed a positive correlation between BMI and failure rates. Their conclusion suggests that patients with a BMI greater than $46 \mathrm{~kg} / \mathrm{m}^{2}$ are at high risk of failure to lose sufficient excess weight one year after AGB surgery. ${ }^{46}$ Other studies identified male gender and African-American race as risk factors for failure. ${ }^{20,45}$

\section{Comparison of banding with other bariatric procedures}

A recent Cochrane review compared AGB with conventional weight loss protocols and several other bariatric procedures. ${ }^{47}$ Three trials reported their findings on conventional therapy versus adjustable gastric banding. ${ }^{48-50}$ At two- to threeyear followup, there was documented statistical benefit in weight loss in the surgical arm versus conventional therapy. In addition, randomized controlled trials including individuals with Type 2 diabetes reported a higher resolution rate and improvements in metabolic syndrome at two years. A 10-year study found a statistically significant improvement in comorbidities of patients who underwent gastric banding.

On the other hand, comparing AGB with other bariatric procedures has shown some benefit in performing the other bariatric procedures. ${ }^{12}$ Agrisani et $a l^{52}$ report that one advantage of LRYGB compared with AGB is better longterm ( $>$ five year) weight loss. On the other hand, AGB was shown to have a shorter operative time, fewer complications, and fewer reoperation rates.

Vertical gastric banding versus AGB was reported in three studies. ${ }^{53-55}$ In these studies, there were missing outcome data and inconclusive weight loss results. In one study, a statistical difference was reported in operative times and duration of hospital stay in favor of AGB.

One study on sleeve gastrectomies versus AGB reported an improvement in comorbidities and lower late complication rates in patients undergoing sleeve gastrectomies, however, sleeve gastrectomies had more early postoperative complications. ${ }^{56}$

A retrospective comparison of biliopancreatic diversion versus AGB reported better weight loss with biliopancreatic diversion. ${ }^{59}$ However, biliopancreatic diversion patients had longer hospital stays and higher complication rates that those who had AGB. Both procedures resulted in similar resolution of comorbidities.

In conclusion, AGB has been proven to be of more benefit than medical weight loss therapy. However in comparison with other bariatric procedures, AGB has its advantages and disadvantages. Although multiple studies have been undertaken comparing AGB with other bariatric procedures, more statistically qualifying trials are need for validation of one procedure over another. It appears that weight loss with AGB is not as good as the other procedures offered; however, the morbidity and mortality of the band is very attractive to many patients as well as to many surgeons.

\section{Complications of laparoscopic AGB}

While the morbidity and mortality of laparoscopic AGB are typically lower than that of the more invasive laparoscopic bariatric stapling procedures, there are still several welldescribed complications specific to gastric banding that may lead to a significant reoperation rate. The number of AGB procedures is increasing in the US, and every surgeon who manages patients with morbid obesity must be able to recognize and manage these complications. 
The overall complication rate for laparoscopic AGB ranges from $12 \%$ to $48 \%$, with larger series reporting a complication rate of about $20 \%$ to $25 \% .^{59-72}$ The complication rates in more recent studies are generally lower than in older studies. This may be attributable to improved surgical techniques and the development of newer band designs. ${ }^{61}$ With this complication rate, there is also a significant reoperative rate ranging from $10 \%$ to $34 \%$, depending on the series reviewed.

Most complications occur late, rather than early. While most series report no mortality, the rare deaths that have been described are primarily because of pulmonary embolism and myocardial infarction. This is a reminder of the significant morbidity associated with this patient population. Therefore, the importance of perioperative deep vein thrombosis prophylaxis and preoperative cardiac evaluation when appropriate on all patients undergoing bariatric surgery regardless of the type of operation, cannot be stressed enough. $^{58}$

\section{Early complications}

Early complications include band obstruction, gastric perforation, wound infection, and bleeding. ${ }^{59,60}$ Careful surgical technique is essential in limiting these early complications. Meticulous dissection should be undertaken during the creation of the retrogastric tunnel so that the chance of a gastric perforation or injury to the spleen is minimized. A gastric or esophageal injury may lead to aborting of band insertion and a splenic injury may prompt an emergency splenectomy. In the majority of cases, band obstruction may be managed conservatively, but if symptoms do not resolve, re-exploration may be necessary. At surgery, removal of the proximal gastric fat pad may be all that is required to relieve the obstruction. In other situations, replacement of the device with a larger size band may be necessary.

\section{Late complications}

Late complications include band slippage, pouch or esophageal dilatation, band erosion, and port/tubing complications. ${ }^{59-70}$ Band slippage or band prolapse occurs when part of the stomach herniates through the band at the top of the stomach. This occurs in about 4\% (1.0\%-6.5\%) of patients in recent studies, with older studies showing a much higher rate of this complication. ${ }^{64,65,71-73}$ The reason for this dramatic reduction in slippage rate is attributed to the use of the pars flaccida technique instead of the less frequently used perigastric approach for the insertion of the gastric band around the proximal stomach. Several studies have demonstrated a reduction in the number of slips from as high as $15 \%$ down to $2 \%$ simply by this change of technique. ${ }^{74}$

Patients may present with vomiting and dysphagia, sometimes to the point of being unable to handle their own oral secretions. Other symptoms include reflux and inadequate weight loss. Abdominal pain is rare but, if present, should alert the surgeon to the possibility of gastric ischemia. ${ }^{75}$ One should also consider the presence of an unrecognized hiatal hernia in these patients. Parikh et al demonstrated that nearly one-third of patients presenting with a band prolapse had a hiatal hernia found during reoperation, ${ }^{59}$ underscoring the importance of identifying and repairing any significant hiatal hernias during initial band insertion.

When a patient presents with these symptoms, the band should be fully deflated. If symptoms persist, a slip or gastroesophageal dilatation should be strongly suspected, and a gastrografin or barium swallow should be obtained. Definitive treatment for gastric prolapse involves surgery. A laparoscopic exploration should be performed to reduce the prolapse and/or to remove or reposition the band. The placement of an anterior gastrogastric fixation suture may also help limit the number of band slippages.

Gastroesophageal dilatation has a similar presentation to band prolapse. Heartburn, nocturnal reflux, dysphagia, and vomiting may occur. The incidence of gastroesophageal dilation ranges from about $5 \%$ to $15 \%$. Reasons for pouch or esophageal dilation may be related to overtightening of the band or malpositioning of the band, which is typically too low. As with band slippages, pouch dilation may be related to the presence of an unrecognized hiatal hernia and should be investigated..$^{59}$ An evaluation for esophageal dysmotility may also be warranted in these patients; however, preoperative manometry may not be predictive of the development of postoperative esophageal dysfunction. ${ }^{72}$ Management of this complication typically entails deflation of the band and dietary modification, with observation of symptoms and followup contrast studies. In the majority of patients, the dilation resolves within six weeks. ${ }^{75-77}$ Subsequently, cautious adjustments can be performed. If the dilation does not resolve with conservative management then surgical intervention may be required. Removal of the band is recommended because there are several long-term deleterious effects of esophageal dilatation, as described by DeMaria et al. ${ }^{78}$ When the band is removed, strong consideration should be given to conversion to a gastric bypass or sleeve gastrectomy because many patients will regain weight after the restriction is removed. 
Band erosion may be considered one of the most serious complications of AGB. The incidence ranges from $1 \%$ to $3 \%$ depending on the series. The occurrence of erosions seems to have decreased in more recent times with the advent of newer band designs that have a high-volume, ${ }^{63-65,69,71}$ low-pressure system, and improved surgical techniques. ${ }^{61,69}$ Band erosion may occur as a result of a tight fundoplication, particularly if the buckle of the band is covered. The buckle may act as a lead point for the erosion. Care should be taken at the initial operation to avoid covering the buckle. Other factors that may play a role in band erosions include serosal injury during insertion, use of nonsteroidal anti-inflammatory agents, increased pressure within the band, and excessive vomiting. ${ }^{71,79,80}$ Any patient who presents with a late port site wound infection should be investigated with an upper endoscopy to rule out intragastric band migration, as this is a well-described presentation for this complication. Other symptoms may include sudden weight regain, abdominal pain, bleeding, or peritonitis. The management of patients with erosions involves endoscopy with potential intraluminal retrieval of the band or a laparoscopic removal of the band, with suture repair of the stomach at the site of the erosion. ${ }^{61,80}$ Whether a conversion to another procedure is done at the time of band removal is surgeon-specific, but most surgeons would simply remove the infected band. Certainly, placement of another band at the time of removal would not be advisable because of the assured risk of infection and recurrent erosion.

Port and tubing issues occur in about $5 \%$ of patients, but may account for up to $11 \%$ in larger series with longer followup..$^{63}$ These complications include saline leaks from the tubing or port, displacement of the port in the subcutaneous space, and port site infections. Port issues usually require some type of surgical intervention. For port site infections, it may be necessary to remove the port with delayed replacement of the reservoir once the infection has cleared. All late port site infections should prompt an investigation for intragastric band migration, as previously discussed. Strict adherence to good sterile technique is extremely important and will help limit these complications. Improvements in port design have helped reduce band leaks that occur because of inadvertent puncture of the tubing as it enters the port in the subcutaneous pocket during band fills. Fluoroscopy may aid in performing fills in patients who have a port that is difficult to access. A water-soluble contrast study may help identify the location of a suspected leak in patients who have a port volume discrepancy. ${ }^{61}$ Port fascial fixation is also very important and adequate fascial bites should be taken to prevent port migration or rotation.

\section{Future of adjustable gastric banding}

The progress of AGB over the past two decades has been rapid. The ease of band placement and relatively safe early outcomes have allowed banding to become a very popular option for patients desiring bariatric surgery. However, longer term followup has shown that adjustable gastric banding can result in complications of band slippage, erosion, or dilation of the gastric pouch or esophagus, as discussed earlier.

The causes of slippage, erosion, or dilation has not been agreed upon by the bariatric surgical community, but a commonly agreed cause is chronic over-adjustment. Chronic pressure on the esophagus or upper gastric pouch from a tightly adjusted band is likely to be detrimental at these sites. So the future of banding is likely going to focus on preventing or controlling bands from being over-tightened.

One future means of over-tightening is the implementation of new adjustment strategies. Use of routine scheduled fluoroscopy for adjustments is not new but implies a method of seeing pouch or esophageal dilation earlier and intervening to prevent progression of dilation. ${ }^{17} \mathrm{~A}$ commonly discussed option that has received early study is use of pressure monitoring of the band during adjustments to determine optimal pressures which could prevent over-tightening. ${ }^{81}$ Bands that could monitor pressure continuously and adjust automatically to high pressure effects would be potentially valuable.

Self-adjusting bands are a reasonable possibility in the future. Imagine a band with a reservoir of fluid, instead of just a port and a computer-driven pump, that could be controlled wirelessly and alter band adjustment by designated parameters. Such a "smart" band could monitor pressure and deflate automatically during times of severe obstruction. The band could tighten to stop a patient from eating after a certain amount of time. It could unfill when a patient lies down to sleep to prevent saliva pooling and aspiration at night. Just the act of periodically relaxing the band on a frequent basis for a small amount of time might help prevent excessive progressive pressure on the stomach and esophagus.

As we look further into the future, the "smart" band concept could expand substantially. The use of a hydraulic system with a port could be replaced with a portless hydraulic system or another mechanical system which would require no balloon and no fluids, possibly achieving more flexibility in remote adjustments as well as durability. Endoluminal 
placement of these devices would also be very attractive to patients who increasingly want fewer incisions or no incisions without compromised efficacy. Looking forward, the simple adjustable band concept has a lot of potential to be a primary technique for maintaining long-term weight loss.

\section{Conclusion}

The idea of restricting caloric intake by gastric banding has been around for 35 years. It has undergone many modifications to improve its safety and efficacy and is continuing to evolve to meet the needs and demands of patients and surgeons who are battling morbid obesity.

Compared with other procedures such as LRYGB, sleeve gastrectomy, or biliopancreatic diversion, the AGB does not offer as much weight loss. However, it is the safety profile that is so appealing to the patients. Most complications of AGB are not life-threatening and can be managed non-operatively or laparoscopically. Most of these complications can be avoided by good surgical technique and attention to detail during the original operation. With its safe track record and the reported average weight loss of about $50 \%$ EWL over two to three years, the AGB is very attractive.

However, as AGB matures in the literature, we are seeing significant weight regain, with \%EWL falling under $40 \%$ by 10 years. This may result in high rates of band removal or revision surgery. It is difficult to assess which patients will do better than others when evaluating patients for AGB surgery. Certain characteristics, like high starting BMI, may indicate the potential for less than optimal weight loss results.

As with all weight loss operations, the patients must continue life-long followup with their physician's office and remain devoted to good nutrition and exercise in order to maintain their weight loss. It is important that patients are constantly reminded that the band acts as a tool to help them lose weight and that it is imperative that they continue to use this tool correctly. To date, there is no "cure" for morbid obesity.

In conclusion, AGB continues to play an important role in the treatment of morbid obesity. It offers reasonably good weight loss results with very little morbidity, and the future of the adjustable band is bright.

\section{Disclosures}

The authors report no conflicts of interest in this work.

\section{References}

1. Buchwald H, Oien DM. Metabolic/bariatric surgery worldwide 2008. Obes Surg. 2009;19:1605-1611.
2. Wilkinson LH. Reduction of gastric reservoir capacity. J Clin Nutr. 1980;33:515-517.

3. Wilkinson LH, Peloso OA. Gastric (reservoir) reduction for morbid obesity. Arch Surg. 1981;116:602.

4. Kolle K. Gastric banding. OMGI 7th Congress, Stockholm. 1982;145: 37. Abstract.

5. Molina M, Oria HE. Gastric segmentation: A new, safe, effective, simple, readily revised and fully reversible surgical procedure for the correction of morbid obesity (Abstract 15). In: 6th Bariatric Surgery Colloquium; Iowa City, IA: June 2-3, 1983.

6. Frydenberg HB. The surgical management of obesity. Aust Fam Physician. 1985;14:1017-1018.

7. Kuzmak LI. Silicone gastric banding: A simple and effective operation for morbid obesity. Contemp Surg. 1986;28:13-18.

8. Bashour SB, Hill RW. The gastro-clip gastroplasty: An alternative surgical procedure for the treatment of morbid obesity. Tex Med. 1985;81:36-38.

9. Naslund E, Grandstrom L, Stockeld D, Backman L. Marlex mesh gastric banding: A 7-12 year follow-up. Obesity Surgery Journal. 1994;4:269-273.

10. Szinicz G, Mueller L, Erhard W, et al. Reversible gastric banding in surgical treatment of morbid obesity - results of animal experiments. Res Exp Med (Berl). 1989;189:55-60.

11. Kuzmak LI. A review of seven years' experience with silicone gastric banding. Obes Surg. 1991;1:403-408.

12. Belachew M, Legrand MJ, Vincent V. History of Lap-Band ${ }^{\circledR}$ : From dream to reality. Obes Surg. 2001;11:297-302.

13. Broadbent R, Tracy M, Harrington P. Laparoscopic gastric banding: A preliminary report. Obes Surg. 1993;3:63-67.

14. Catona A, Gossenberg M, La Manna A. Laparoscopic gastric banding: Preliminary series. Obes Surg. 1993;3:207-209.

15. Belachew M, Legrand M, Vincent V, Lismonde M, Docte N, Duschampes V. Laparoscopic adjustable banding. World J Surg. 1998;22:955-963.

16. Favretti F, Ashton D, Busetto L, et al. The gastric band: First choice procedure for obesity surgery. World J Surg. 2009;33:2039-2048.

17. Cherian PT, Tentzeris V, Sigurdsson A. Variation of outcome in weight loss with band volume adjustments under clinical and radiologic control following laparoscopic adjustable gastric banding. Obes Surg. 2009; [Epub ahead of print].

18. Garb J, Welch G, Zagarins S, et al. Bariatric surgery for the treatment of morbid obesity: A meta analysis of weight loss outcomes for laparoscopic adjustable gastric banding and laparoscopic gastric bypass. Obes Surg. 2009;19:1447-1455.

19. Nadler EP, Youn HA, Ren CJ, et al. An update on 73 US obese pediatric patients treated with laparoscopic adjustable gastric banding: Comorbidity resolution and compliance data. J Pediatr Surg. 2009;43:141-146.

20. Nguyen NT, Slone JA, Nguyen XMT, et al. A prospective randomized trial of laparoscopic gastric bypass versus laparoscopic adjustable gastric banding for the treatment of morbid obesity: Outcomes, quality of life, and costs. Ann Surg. 2009;250:631-639.

21. Weiner R, Blanco-Engert R, Weiner S, et al. Outcome after laparoscopic adjustable gastric banding -8 years experience. Obes Surg. 2003;13:427-434.

22. Brancatisano A, Wahlroos S, Matthews S, et al. Gastric banding for the treatment of type 2 diabetes mellitus in morbidly obese. Surg Obes Relat Dis. 2008;4:423-429.

23. Brancatisano A, Wahlroos $S$, Brancatisano R. Improvement in comorbid illness after placement of the Swedish Adjustable Gastric Band. Surg Obes Relat Dis. 2008;4(3 Suppl):S39-S46.

24. Ahroni JH, Montgomery KF, Watkins BM. Laparoscopic adjustable gastric banding: Weight loss, co-morbidities, medication usage and quality of life at one year. Obes Surg. 2005;15:641-647.

25. Rubenstein RB. Laparoscopic adjustable gastric banding at a US center with up to 3-year follow-up. Obes Surg. 2002;12:380-384.

26. Brethauer SA, Chand B, Schauer PR. Risks and benefits of bariatric surgery: Current evidence. Cleve Clin J Med. 2006;73:993-1007. 
27. Chapman AE, et al. Laparoscopic adjustable gastric banding in the treatment of obesity: A systematic literature review. Surgery. 2004;135:326-351.

28. Ponce J, Paynter S, Fromm R. Laparoscopic adjustable gastric banding: 1,014 consecutive cases. J Am Coll Surg. 2005;201:529-535.

29. Weiner R, et al. Outcome after laparoscopic adjustable gastric banding - 8 years experience. Obes Surg. 2003;13:427-434.

30. O'Brien PE, Brown WA, Smith A, McMurrick PJ, Stephens M. Prospective study of a laparoscopically placed, adjustable gastric band in the treatment of morbid obesity. Br J Surg. 1999;86:113-118.

31. Zehetner J, Holzinger F, Triaca H, Klaiber CH. A 6-year experience with the Swedish adjustable gastric band: Prospective long-term audit of laparoscopic gastric banding. Surg Endosc. 2005;19:21-28.

32. Shen R, Dugay G, Rajaram K, Cabrera I, Siegel N, Ren CJ. Impact of patient follow-up on weight loss after bariatric surgery. Obes Surg. 2004;14:514-519.

33. Papalazarou A, Yannakoulia M, Kavouras SA, et al. Lifestyle intervention favorably affects weight loss and maintenance following obesity surgery. Obesity. 2009; 10:103.

34. Colles SL, Dixon JB, O'Brien PE. Grazing and loss of control related to eating: two high-risk factors following bariatric surgery. Obesity. 2008;16:615-622.

35. Favretti F, O'Brien PE, Dixon JB. Patient management after LAP-BAND placement. Am J Surg. 2002;184:38S-41S.

36. Tucker ON, Szomstein S, Rosenthal RJ. Nutritional consequences of weight-loss surgery. Med Clin N Am. 2007:499-514.

37. Seok YT, Zarshenas N, Jorgensen J. Prevalence of nutrient deficiencies in bariatric patients. Nutrition. 2009;25:1150-1156.

38. Parkes E. Nutritional management of patients after bariatric surgery. Am J Med Sci. 2006;331:207-213.

39. Coupaye M, Puchaux K, Bogard C, et al. Nutritional consequences of adjustable gastric banding and gastric bypass: A 1-year prospective study. Obes Surg. 2009;19:56-65.

40. Aills L, Blankenship J, Buffington C, Furtado M, Parrott J. ASMBS allied health nutritional guidelines for the surgical weight loss patient. Surg Obes Relat Dis. 2008;4:S73-S108.

41. Tolonen P, Victorzon M, Mäkelä J. 11-year experience with laparoscopic adjustable gastric banding for morbid obesity - what happened to the first 123 patients? Obes Surg. 2008;18:251-255.

42. Biertho L, Steffen R, Branson R, et al. Management of failed adjustable gastric banding. Surgery. 2005;137:33-41.

43. Snyder B, Nguyen A, Scarbourough T, et al. Comparison of those who succeed in losing significant excessive weight after bariatric surgery and those who fail. Surg Endosc. 2009;23:2302-2306.

44. Kothari SN, DeMaria EJ, Sugerman HJ, et al. Lap-band failures: Conversion to gastric bypass and their preliminary outcomes. Surgery. 2002;131:625-629.

45. DeMaria EJ, Sugerman HJ, Meador JG, et al. High failure rate after laparoscopic adjustable silicone gastric banding for treatment of morbid obesity. Ann Surg. 2001;233:809-818.

46. Snyder B, Scarborough T, Yu S, et al. Failure of adjustable gastric banding: Starting BMI of $46 \mathrm{~kg} / \mathrm{m}^{2}$ is a fulcrum of success and failure. Surg Obes Relat Dis. 2009;5:310-316.

47. Colquitt JL, Picot J, Loveman E, Clegg AJ. Surgery for obesity. Cochrane Database Syst Rev. 2009;15:CD003641.

48. Dixon JB, O'Brien PE, Playfair J, et al. Adjustable gastric banding and conventional therapy for type 2 diabetes: A randomized controlled trial. JAMA. 2008;299:316-323.

49. O'Brien PE, Dixon JB, Laurie C, et al. Treatment of mild to moderate obesity with laparoscopic adjustable gastric banding or an intensive medical program: A randomized trial. Ann Intern Med. 2006;144:625-633.

50. Stoeckli R, Chanda R, Langer I, Keller U. Changes of body weight and plasma ghrelin levels after gastric banding and gastric bypass. Obes Res. 2004;12:346-350.

51. Buchwald H, Avidor Y, Braunwald E, et al. Bariatric surgery: A systematic review and meta-analysis. JAMA. 2004;292:1724-1737. Erratum: JAMA. 2005;293:1728.
52. Agrisani A, Lorenzo M, Borrrelli V. Laparoscopic adjustable gastric banding versus Roux-en-Y gastric bypass: 5-year results of a prospective randomized trial. Surg Obes Rel Dis. 2007;3:127-133.

53. Nilsell K, Thorne A, Sjostedt S, et al. Prospective randomized comparison of adjustable gastric banding and vertical banded gastroplasty for morbid obesity. Eur J Surg. 2001;167:504-509.

54. Morino M, Toppino M, Bonnet G, et al. Laparoscopic adjustable silicone gastric banding versus vertical banded gastroplasty in morbidly obese patients: A prospective randomized controlled clinical trial. Ann Surg. 2003;238:835-841.

55. VanDielen FM, Soeters PB, de Brauw LM, et al. Laparoscopic adjustable gastric banding versus open vertical banded gastroplasty: A prospective randomized trial. Obes Surg. 2005;15:1292-1298.

56. Himpens J, Dapri G, Cadiere GB. A prospective randomized study between laparoscopic gastric banding and laparoscopic isolated sleeve gastrectomy: Results after 1 and 3 years. Obes Surg. 2006;16:1450-1456.

57. Dolan K, Hatzifotis M, Newbury L, Fielding G. A comparison of laparoscopic adjustable gastric banding and biliopancreatic diversion in superobesity. Obes Surg. 2004 Feb;14:165-169.

58. Gagner M, Milone L, Yung E, Broseus A, Gumbs AA. Causes of early mortality after laparoscopic adjustable gastric banding. J Am Coll Surg. 2008;206:664-669.

59. Parikh MS, Fielding GA, Ren CJ. US experience with 749 laparoscopic adjustable gastric bands: Intermediate outcomes. Surg Endosc. 2005;19:1631-1635.

60. Carucci LR, Turner MA, Szucs RA. Adjustable laparoscopic gastric banding for morbid obesity: Imaging assessment and complications. Radiol Clin North Am. 2007;45:261-274.

61. Mittermair R, Aigner F, Obermüller S. High complication rate after Swedish adjustable gastric banding in younger patients $<$ or $=25$ years. Obes Surg. 2009;19:446-450.

62. Suter M, Calmes JM, Paroz A, Giusti V. A 10-year experience with laparoscopic gastric banding for morbid obesity: High long-term complication and failure rates. Obes Surg. 2006;16:829-835.

63. Mittermair RP, Obermüller S, Perathoner A, Sieb M, Aigner F, Margreiter R. Results and complications after Swedish adjustable gastric banding - 10 years experience. Obes Surg. 2009;19: 1636-1641.

64. Tolonen P, Victorzon M, Mäkelä J. 11-year experience with laparoscopic adjustable gastric banding for morbid obesity - what happened to the first 123 patients? Obes Surg. 2008;18:251-255.

65. Mittermair RP, Aigner F, Obermüller S. Results and complications after Swedish adjustable gastric banding in older patients. Obes Surg. 2008;18:1558-1562.

66. Sarker S, Myers J, Serot J, Shayani V. Three-year follow-up weight loss results for patients undergoing laparoscopic adjustable gastric banding at a major university medical center: Does the weight loss persist? Am J Surg. 2006;191:372-376.

67. Sultan S, Parikh M, Youn H, Kurian M, Fielding G, Ren C. Early US outcomes after laparoscopic adjustable gastric banding in patients with a body mass index less than $35 \mathrm{~kg} / \mathrm{m}^{2}$. Surg Endosc. 2009;23: 1569-1573.

68. Tice JA, Karliner L, Walsh J, Petersen AJ, Feldman MD. Gastric banding or bypass? A systematic review comparing the two most popular bariatric procedures. Am J Med. 2008;121:885-893.

69. Biagini J, Karam L. Ten years experience with laparoscopic adjustable gastric banding. Obes Surg. 2008;18:573-577.

70. Naef M, Naef U, Mouton WG, Wagner HE. Outcome and complications after laparoscopic Swedish adjustable gastric banding: 5-year results of a prospective clinical trial. Obes Surg. 2007;17:195-201.

71. Balsiger BM, Ernst D, Giachino D, Bachmann R, Glaettli A. Prospective evaluation and 7-year follow-up of Swedish adjustable gastric banding in adults with extreme obesity. J Gastrointest Surg. 2007;11: 1470-1476.

72. Parikh MS, Laker S, Weiner M, Hajiseyedjavadi O, Ren CJ. Objective comparison of complications resulting from laparoscopic bariatric procedures. J Am Coll Surg. 2006;202:252-261. 
73. Nguyen NT, Wilson SE. Complications of antiobesity surgery. Nat Clin Pract Gastroenterol Hepatol. 2007;4:138-147.

74. O'Brien PE, Dixon JB. The extent of the problem of obesity. Am J Surg. 2002;184:4S-8S.

75. Allen JW. Laparoscopic gastric band complications. Med Clin North Am. 2007;91:485-497, xii.

76. Arias IE, Radulescu M, Stiegeler R, et al. Diagnosis and treatment of megaesophagus after adjustable gastric banding for morbid obesity. Surg Obes Relat Dis. 2009;5:156-159.

77. Milone L, Daud A, Durak E, et al. Esophageal dilation after laparoscopic adjustable gastric banding. Surg Endosc. 2008;22:1482-1486.
78. DeMaria EJ, Sugerman HJ, Meador JG, et al. High failure rate after laparoscopic adjustable silicone gastric banding for treatment of morbid obesity. Ann Surg. 2001;233:809-818.

79. Ren CJ, Fielding GA. Laparoscopic adjustable gastric banding [Lap-Band]. Curr Surg. 2003;60:30-33.

80. Nocca D, Frering V, Gallix B, et al. Migration of adjustable gastric banding from a cohort study of 4236 patients. Surg Endosc. 2005;19: 947-950.

81. Lechner W, Gadenstätter M, Ciovica R, Kirchmayr W, Schwab G. In vivo band manometry: A new access to band adjustment. Obes Surg. $2005 ; 15: 1432-1436$.

\section{Publish your work in this journal}

Diabetes, Metabolic Syndrome and Obesity: Targets and Therapy is an international, peer-reviewed open-access journal committed to the rapid publication of the latest laboratory and clinical findings in the fields of diabetes, metabolic syndrome and obesity research. Original research, review, case reports, hypothesis formation, expert opinion and commentaries are all considered for publication. The manuscript management system is completely online and includes a very quick and fair peer-review system, which is all easy to use. Visit http://www.dovepress.com/testimonials.php to read real quotes from published authors.

Submit your manuscript here: http://www.dovepress.com/diabetes-metabolic-syndrome-and-obesity-targets-and-therapy-journal 